\title{
Constitutive activation of the G-protein subunit Gos within forebrain neurons causes PKA-dependent alterations in fear conditioning and cortical Arc mRNA expression
}

\author{
Michele P. Kelly, ${ }^{1,2,5,6}$ York-Fong Cheung, ${ }^{3}$ Christopher Favilla, ${ }^{1}$ Steven J. Siegel, ${ }^{2}$ \\ Stephen J. Kanes, ${ }^{2,4}$ Miles D. Houslay, ${ }^{3}$ and Ted Abel ${ }^{1}$ \\ ${ }^{1}$ Department of Biology, University of Pennsylvania, Philadelphia, Pennsylvania 19104, USA; ${ }^{2}$ Department of Psychiatry, \\ University of Pennsylvania, Philadelphia, Pennsylvania 19104, USA; ${ }^{3}$ Division of Biochemistry and Molecular Biology, \\ Institute of Biomedical and Life Sciences, University of Glasgow, Glasgow G12 8QQ, Scotland, United Kingdom
}

\begin{abstract}
Memory formation requires cAMP signaling; thus, this cascade has been of great interest in the search for cognitive enhancers. Given that medications are administered long-term, we determined the effects of chronically increasing cAMP synthesis in the brain by expressing a constitutively active isoform of the G-protein subunit $G \alpha s\left(G \alpha s^{*}\right)$ in postnatal forebrain neurons of mice. Previously, we showed that $G \alpha s^{*}$ mice exhibit increased adenylyl cyclase activity but decreased cAMP levels in cortex and hippocampus due to a PKA-dependent increase in total cAMP phosphodiesterase (PDE) activity. Here, we extend previous findings by determining if $G \alpha s^{*}$ mice show increased activity of specific PDE families that are regulated by PKA, if G $\alpha s^{*}$ mice show PKA-dependent deficits in fear memory, and if these memory deficits are associated with PKA-dependent alterations in neuronal activity as mapped by Arc mRNA expression. Consistent with previous findings, we show here that Gos* mice exhibit a significant compensatory increase in CAMP PDE1 activity and a trend toward increased cAMP PDE4 activity. Further, inhibiting the presumably elevated PKA activity in Gos ${ }^{*}$ mice fully rescues short- and long-term memory deficits in a fear-conditioning task, while extending the training session from one to four CS-US pairings partially rescues these deficits. Mapping of Arc mRNA levels suggests these PKA-dependent memory deficits may be related to decreased neuronal activity specifically within the cortex. Gos $s^{*}$ mice show decreased Arc mRNA expression in CAl, orbital cortex, and cortical regions surrounding the hippocampus; however, only the deficits in cortical regions surrounding the hippocampus are PKA dependent. Our results imply that chronically stimulating targets upstream of cAMP may detrimentally affect cognition.
\end{abstract}

Regulated signaling through the cAMP cascade is key to the neurobiology of learning and memory (Livingstone et al. 1984; Connolly et al. 1996; Wong et al. 1999; Pineda et al. 2004). Studies in flies and mice show that both decreases (Livingstone et al. 1984; Wong et al. 1999) and increases (Connolly et al. 1996; Pineda et al. 2004) in adenylyl cyclase (AC) activity can result in memory deficits. Similarly, decreasing cAMP-dependent protein kinase A (PKA) activity impairs hippocampus-dependent memory (Abel et al. 1997), whereas increasing PKA activity impairs prefrontal cortex-dependent memory in mice (Ramos et al. 2003). There does, however, appear to be a window within which the cAMP cascade can be positively modulated to enhance memory. For example, overexpression of AC type 1 in mice enhances recognition memory (Wang et al. 2004). Further, pharmacological inhibition of cAMP phosphodiesterases (PDE), the only enzymes that degrade cAMP (cf. Beavo and Brunton 2002; Houslay and Adams 2003), improves baseline memory in mice (Barad et al. 1998; Monti et al. 2006) and rescues genetically (Bourtchouladze

\footnotetext{
Present addresses: ${ }^{4}$ AstraZeneca LP, FOC-SW1-938, 1800 Concord Pike, P.O. Box 15437, Wilmington, DE 19850-5437, USA; ${ }^{5}$ Wyeth Research, Department of Neuroscience, 865 Ridge Rd., Room 1733, Monmouth Junction, NJ 08852, USA.

${ }^{6}$ Corresponding author.

E-mail kellym22@wyeth.com; fax (732) 274-4755.

Article is online at http://www.learnmem.org/cgi/doi/10.1101/lm.723708.
}

et al. 2003) and pharmacologically induced memory deficits (Zhang et al. 2000, 2004). As a result, the cAMP cascade has been of great interest in the search for therapeutics that will treat cognitive deficits (cf. Barco et al. 2003; Houslay et al. 2005).

If we are to exploit the cAMP cascade for therapeutic gain, it is critically important that we understand the biochemical and behavioral impact of chronically altering signaling within this pathway, given that medications are likely to be administered long-term. Previously, we showed that transgenic mice expressing a constitutively active isoform of the G-protein subunit Gas $\left(G \alpha S^{*}\right)$ within forebrain neurons exhibit increased AC activity in cortex and hippocampus but decreased cAMP levels in these regions (Kelly et al. 2007). These G $\alpha s^{*}$-induced decreases in cAMP are due to a compensatory up-regulation of cAMP PDE activity (Kelly et al. 2007) and are rescued by co-expression of $\mathrm{R}(\mathrm{AB})$ (Kelly et al. 2007), a transgene encoding a dominant-negative regulatory subunit of PKA (Abel et al. 1997). These compensatory biochemical changes appear to be behaviorally relevant because either genetic inhibition of PKA or pharmacological inhibition of PDE4 by rolipram reverses sensorimotor gating deficits exhibited by $\mathrm{G} \alpha \mathrm{s}^{*}$ mice (Kelly et al. 2007). The fact that rolipram rescues the gating deficits exhibited by Gos* mice suggests that PDE4 activity, specifically, is increased in G $\alpha \mathrm{s}^{*}$ mice. It remains to be determined, however, which PDE family (or families) accounts for the PKA-dependent up-regulation in total cAMP PDE activity. 
Certainly, PKA activates certain isoforms of PDE4 directly through phosphorylation (e.g., MacKenzie et al. 2002) or indirectly through increased transcription (e.g., Vicini and Conti 1997). Additionally, PKA activation can lead to the redistribution of specific PDE4 isoforms between functionally distinct compartments within neurons, as PKA stimulates the selective release of certain PDE4 isoforms from Disrupted in Schizophrenia 1 (Murdoch et al. 2007). The functional consequence of PKA on other families, however, is less well understood. For example, while in vitro evidence suggests that certain isoforms of the PDE1 family are inhibited by PKA directly (Sharma and Wang 1986), work in fungi and yeast suggests that PKA can stimulate PDE1 activity (Ma et al. 1999; Hicks et al. 2005). As such, one aim of the present study is to determine if $\mathrm{G} \alpha \mathrm{s}^{*}$ triggers an increase in cAMP hydrolysis by the PDE1 and/or PDE4 family.

In addition to sensorimotor gating deficits, $\mathrm{G} \alpha \mathrm{s}^{*}$ mice also show learning and memory impairments in the Morris water maze and Pavlovian fear conditioning (Bourtchouladze et al. 2006). The spatial memory impairments exhibited by G $\alpha s^{*}$ mice in the water maze are likely related to the cAMP deficits measured in the hippocampus (Kelly et al. 2007) as this brain region is key to spatial learning (Morris et al. 1990; Blum et al. 1999; Burgess et al. 2002). It is less clear, however, in which brain region ${\mathrm{G} \alpha \mathrm{s}^{*}}^{*}$ acts to affect fear conditioning, given that cAMP levels remain normal in the amygdala of transgenic mice (Kelly et al. 2007). It also remains to be determined if the learning and memory impairments of ${\mathrm{G} \alpha \mathrm{s}^{*}}^{*}$ mice are PKA-dependent as are the cAMP and sensorimotor gating deficits measured in these animals (Kelly et al. 2007). Thus, in addition to determining if $\mathrm{G}_{\alpha} \mathrm{s}^{*}$ causes an up-regulation in the activity of PKA-regulated PDEs, we test here if the $G \alpha \mathrm{S}^{*}$-induced deficits in fear memory are PKA-dependent and in which brain region these memory deficits are associated with PKA-dependent alterations in neuronal activity, as mapped by changes in mRNA levels of the activity-regulated immediateearly gene Arc (Link et al. 1995; Lyford et al. 1995; Guzowski et al. 1999; Kelly and Deadwyler 2003; Temple et al. 2003; Gusev et al. 2005). In addition, we determine if increasing the amount of training (from one to four conditioned stimulus-unconditioned stimulus pairings) and providing both contextual and auditory memory-related cues during retrieval is sufficient to overcome the $\mathrm{G} \alpha \mathrm{S}^{*}$-induced deficits in fear memory and neuronal activation. If the cAMP cascade is to be therapeutically exploited, we must gain a full understanding of the region-specific feedforward and feedback mechanisms at play in the brain and how these molecular mechanisms may differentially regulate memory.

\section{Results}

\section{$\mathrm{G} \alpha \mathrm{s}^{*}$ induces compensatory increases in cAMP hydrolysis by specific PDE families.}

To gain a better understanding of the intracellular signaling events that mediate the effect of $G \alpha s^{*}$ on memory, we measured activity levels of specific cAMP PDE families in cortex of G $\alpha \mathrm{s}^{*}$ $(n=12-13)$ vs. WT mice $(n=13-14)$. We focused our analyses on PDE families that hydrolyze cAMP, are regulated by PKA activity either directly or indirectly, are present in cortex, and for which specific inhibitors are available-namely, PDE4 (cAMP hydrolyzing) and PDE1 (cAMP and cGMP hydrolyzing). Gas* mice exhibit an increase in PDE4 activity $(116.68 \% \pm 9.6 \%)$ relative to wild-type mice $(100.00 \% \pm 3.6 \%)$; however, this difference is not statistically significant $\left(t_{(23)}=1.67, P=0.11\right)$. Consistent with this minimal effect on PDE4 activity, the cAMP PDE activity remaining after PDE4 activity is inhibited (referred to as residual activity) is greater in $\mathrm{G} \alpha \mathrm{s}^{*}$ mice $\left(t_{(23)}=2.04, P=0.05\right)$. In contrast, G $\alpha \mathrm{s}^{*}$ mice show a clear increase in PDE1 activity
$(132.54 \% \pm 10.7 \%)$ relative to wild-type mice $(100.00 \% \pm 7.3 \%$; $\left.t_{(25)}=2.55, P<0.02\right)$. It appears that this increase in PDE1 activity may be largely responsible for the increase in total cAMP PDE activity measured in $\mathrm{G} \alpha \mathrm{s}^{*}$ mice because the residual cAMP PDE activity that remains when PDE1 is inhibited does not significantly differ between $G \alpha s^{*}$ and wild-type mice $\left(t_{(23)}=1.48\right.$, $P=0.15)$.

\section{Experiment 1}

\section{Genetic inhibition of PKA rescues fear-conditioning deficits in Gos* mice}

To determine if $\mathrm{G}_{\alpha} \mathrm{S}^{*}$ causes PKA-dependent deficits in fear conditioning, wild-type, $\mathrm{G} \alpha \mathrm{s}^{*}, \mathrm{R}(\mathrm{AB})$, and $\mathrm{G} \alpha \mathrm{s}^{*} \times \mathrm{R}(\mathrm{AB})$ mice were trained to associate a footshock (unconditioned stimulus, US) with an auditory cue (conditioned stimulus, CS; Experiment 1). During training, mice show no pre-CS freezing but equivalently low levels of unconditioned freezing to the cue (prior to presentation of the US; WT $8.57 \% \pm 4.0 \%$; Gos ${ }^{*} 5.00 \% \pm 3.3 \%$; R(AB) $10.00 \% \pm 4.6 \%$; $\left.\mathrm{G}_{\alpha} \mathrm{s}^{*} \times \mathrm{R}(\mathrm{AB}) 0.00 \% \pm 0 \%\right)$. Similarly, there is no difference between genotypes in the level of freezing observed immediately following the US (post-US; Fig. 1B). During testing for short-term memory, mice do not show a significant difference in pre-CS freezing; however, there is a striking difference across genotypes in levels of conditioned freezing to the CS $\left(F_{(3,37)}=29.93, P<0.001\right)$. Post-hoc analyses reveal that $\mathrm{G} \alpha \mathrm{s}^{*}$

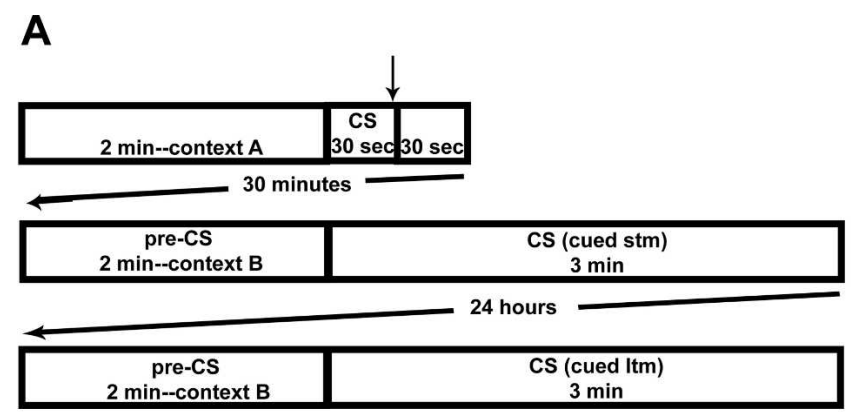

B

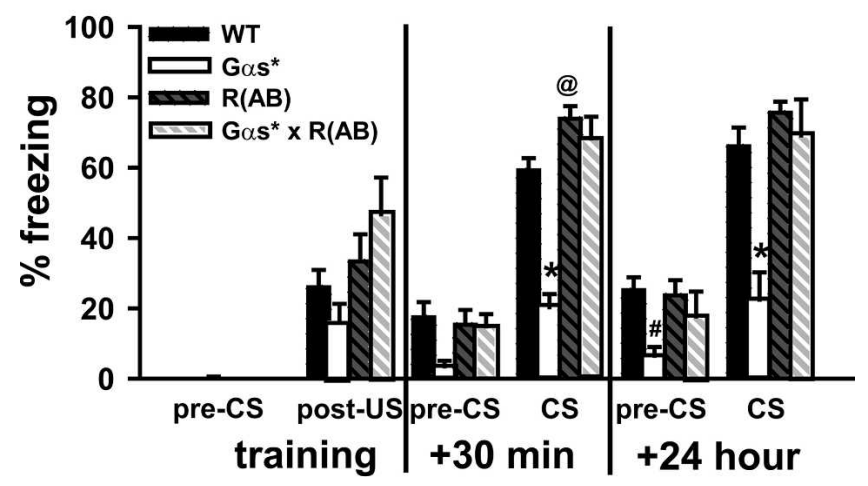

Figure 1. G $\alpha s^{*}$ mice exhibit PKA-dependent deficits in short-term and long-term fear memory. (A) Wild-type (WT, $n=14), \mathrm{G} \alpha \mathrm{s}^{*}(n=8), \mathrm{R}(\mathrm{AB})$ $(n=12)$, and $\mathrm{G} \alpha \mathrm{s}^{*} \times \mathrm{R}(\mathrm{AB})$ mice $(n=7)$ were trained to associate a conditioned auditory stimulus (CS) with a 2 -sec $1.5-\mathrm{mA}$ footshock (unconditioned stimulus, US). Small vertical arrow indicates onset of the US. (B) G $\alpha s^{*}$ mice show normal levels of freezing during the training session but significantly lower levels of freezing relative to all other genotypes during both short-term memory ( $+30 \mathrm{~min})$ and long-term memory (+24 h) tests. (*) Post-hoc vs. WT, R(AB), and $G \alpha s^{*} \times R(A B), P<0.001$; (@) post-hoc vs. WT, $P<0.05$; (\#) post-hoc vs. WT and R(AB), $P<0.02$. 
mice show drastically lower levels of freezing to the cue relative to $\mathrm{WT}, \mathrm{R}(\mathrm{AB})$, and $\mathrm{G} \alpha \mathrm{S}^{*} \times \mathrm{R}(\mathrm{AB})$ mice (each group, $\left.P<0.001\right)$. In addition, $\mathrm{R}(\mathrm{AB})$ mice show higher levels of freezing relative to WT mice $(P<0.02)$. During testing for long-term memory, mice show a small but significant difference in levels of pre-CS freezing $\left(F_{(3,37)}=3.41, P<0.05\right)$. Post-hoc analyses show that $G \alpha s^{*}$ mice exhibit lower levels of freezing relative to WT and $\mathrm{R}(\mathrm{AB})$ mice only (for each, $P<0.05$ ). During presentation of the CS, however, the difference across genotypes is much greater $\left(F_{(3,37)}=13.23\right.$, $P<0.001)$. Post-hoc analyses reveal that ${\mathrm{G} \alpha \mathrm{s}^{*}}^{*}$ mice show drastically lower levels of freezing to the cue relative to WT, R(AB), and $\mathrm{G}_{\alpha \mathrm{S}^{*}} \times \mathrm{R}(\mathrm{AB})$ mice (for each group, $P<0.001$ ). Even when the differences in pre-CS freezing are accounted for by comparing the extent to which the CS increases freezing above pre-CS levels, $\mathrm{G} \alpha \mathrm{S}^{*}$ mice exhibit significantly less freezing during the CS relative to $\mathrm{WT}, \mathrm{R}(\mathrm{AB})$, and $\mathrm{G} \alpha \mathrm{S}^{*} \times \mathrm{R}(\mathrm{AB})$ mice $\left(F_{(3,37)}=11.50\right.$, $P<0.001$; post-hoc vs. G $\alpha \mathrm{s}^{*}$ for each group, $\left.P<0.001\right)$. The fact that $\mathrm{G} \alpha \mathrm{s}^{*} \times \mathrm{R}(\mathrm{AB})$ bigenic mice show normal levels of freezing to the cue $30 \mathrm{~min}$ and $24 \mathrm{~h}$ following training shows that $\mathrm{G} \alpha \mathrm{s}^{*}$ causes PKA-dependent deficits in short-term and long-term fear memory.

\section{Gos $s^{*}$ mice exhibit PKA-dependent decreases in cortical activity as mapped by Arc mRNA}

To determine if $G \alpha s^{*}$ causes region-specific PKA-dependent deficits in neuronal activity, we mapped mRNA levels of Arc (Lyford et al. 1995), an immediate-early gene regulated by neuronal activity (e.g., Guzowski et al. 1999; Kelly and Deadwyler 2003; Temple et al. 2003; Gusev et al. 2005). Of particular interest to the current study, in vitro evidence suggests that Arc transcription is regulated by cAMP and PKA signaling (Waltereit et al. 2001); however, this has yet to be established in vivo. Further, genetic deletion of Arc causes cued fear-conditioning deficits (Plath et al. 2006).

Arc mRNA levels measured across cortical regions surrounding the hippocampus (visual, VIS; parietal association, PAR; somatosensory, SOM; entorhinal, ENT) show a significant effect of transgene expression (Fig. $2 \mathrm{~A} ; F_{(3,184)}=5.23, P<0.005$ ). Post-hoc analyses reveal that $\mathrm{G} \alpha \mathrm{S}^{*}$ transgenic mice show significantly reduced Arc mRNA levels relative to wild-type, $\mathrm{R}(\mathrm{AB})$, and $\mathrm{G} \alpha \mathrm{S}^{*} \times \mathrm{R}(\mathrm{AB})$ mice $\left(\mathrm{G} \alpha \mathrm{S}^{*}\right.$ vs. each, $\left.P<0.02\right)$. Further, neither $\mathrm{R}(\mathrm{AB})$ nor $\mathrm{G} \alpha \mathrm{s}^{*} \times \mathrm{R}(\mathrm{AB})$ mice significantly differ from wild-type mice in cortical Arc mRNA levels. G $\alpha s^{*}$ mice also exhibit significantly reduced $\operatorname{Arc}$ mRNA levels in orbital cortex (ORB; Fig. 2B; $\left.F_{(3,53)}=3.74, P<0.02\right)$ but only relative to wild-type and $\mathrm{R}(\mathrm{AB})$ mice (post hoc, $P<0.05$ for each). Surprisingly, there is no significant effect of genotype on basal Arc mRNA levels across hippocampal subregions when all genotypes are analyzed together (CA1 and CA3; Fig. 2C). Lastly, there is no effect of genotype on basal Arc mRNA expression of the medial caudate putamen (CPu; Fig. 2D), but see below results for the lateral caudate putamen. The fact that co-expression of $\mathrm{R}(\mathrm{AB})$ rescues the Arc mRNA deficits observed in cortical regions surrounding the hippocampus of $\mathrm{G} \mathrm{s}^{*}$ mice shows that these alterations are PKAdependent.

\section{Experiment 2}

Increased training rescues short-term but not long-term fear memory in $\mathrm{G} \alpha{ }^{*}$ mice

To determine if providing additional training and retrieval cues could improve memory-based performance in Gas* mice, subjects were trained with four CS-US pairings and were presented with both contextual and auditory cues during retrieval. Despite
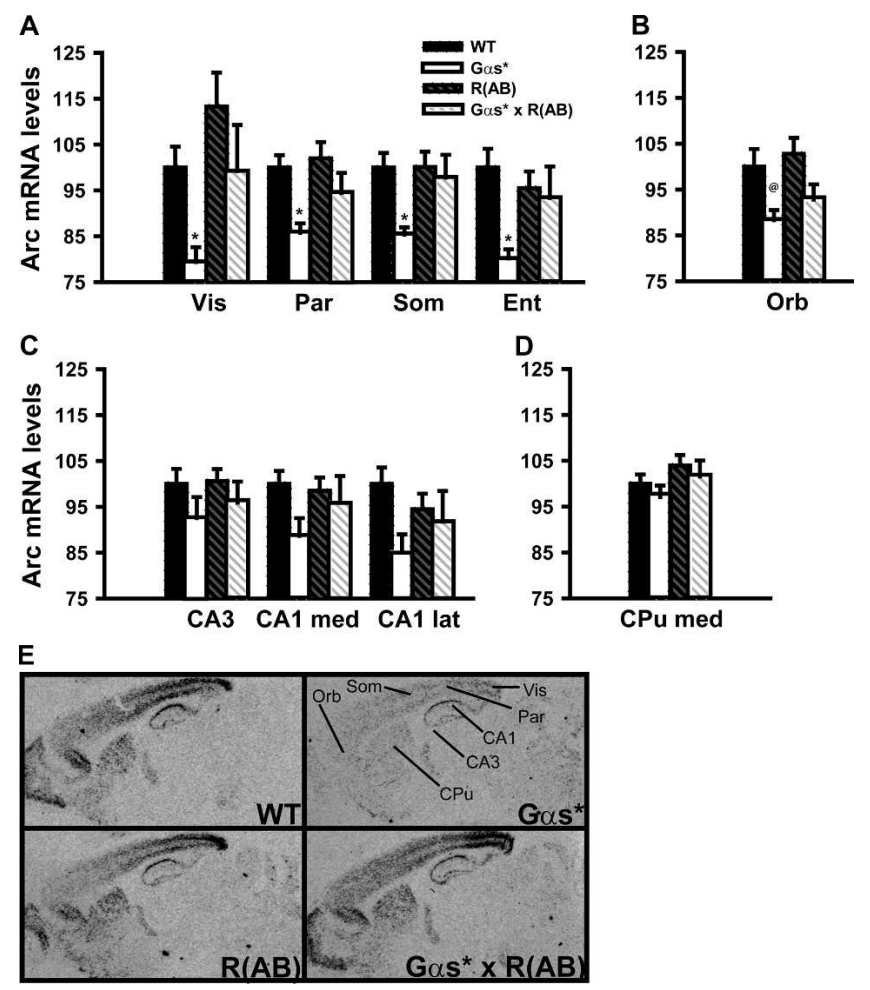

Figure 2. G $\alpha s^{*}$ mice exhibit PKA-dependent deficits in neuronal activity within cortex as indicated by reduced basal Arc mRNA expression. Arc mRNA levels (\% WT) were quantified in wild-type (WT, $n=16-17)$, G $\alpha s^{*}$ $(n=12-13), \mathrm{R}(\mathrm{AB})(n=16-17)$, and $\mathrm{G} \alpha \mathrm{s}^{*} \times \mathrm{R}(\mathrm{AB})$ mice $(n=6-7)$ across $(A)$ cortical regions surrounding the hippocampus (Vis, visual; Par, parietal association; Som, somatosensory; Ent, entorhinal), $(B)$ the orbital cortex (Orb), (C) the hippocampal subregions, and $(D)$ the medial caudate putamen (CPu; med, medial; lat, lateral) (see Fig. 4 for Arc expression in lateral $\mathrm{CPu}$ ). Data are collapsed across two cohorts of animals, the first naive to fear conditioning and the second sacrificed $8 \mathrm{~d}$ following training (see Materials and Methods for further details). (E) Autoradiographs show Arc mRNA expression in animals from the second cohort. ${ }^{*}$ Post-hoc vs. WT, R(AB), and G $\alpha s^{*} \times \mathrm{R}(\mathrm{AB}), P<0.02$; ${ }^{\circledR}$ post-hoc vs. WT and $R(A B), P<0.05$.

training with four CS-US pairings, G $\alpha \mathrm{S}^{*}$ mice exhibit significantly lower levels of freezing when returned to the training context for short-term and long-term memory tests $\left(F_{(1,10)}=15.59\right.$, $P<0.005)$. In contrast, training Gas* mice with four CS-US pairings is sufficient to rescue levels of freezing elicited by the CS during the short-term, but not the long-term, memory test (Fig. 3B; $F_{(2,10)}=14.08, P<0.005$; post-hoc WT vs. G $\alpha \mathrm{s}^{*}$, stm, $P=$ NS; 1 tm,$P<0.001)$. These results suggest a dissociation between mechanisms regulating contextual vs. cued memory deficits in $\mathrm{G} \alpha \mathrm{s}^{*}$ mice and show that $\mathrm{G} \alpha \mathrm{s}^{*}$ mice are capable of exhibiting high levels of freezing.

\section{$G \alpha s^{*}$ mice show significantly reduced levels of Arc mRNA in cortex following training with four CS-US pairings due to lower basal levels} Next we determined if $\mathrm{G} \mathrm{s}^{*}$ mice show diminished activation of brain regions following training with four CS-US pairings, in addition to impairments in basal activity. To do so, we compared Arc mRNA levels in $\mathrm{G}^{*} \mathrm{~s}^{*}$ and wild-type mice sacrificed $30 \mathrm{~min}$ following training with four CS-US pairings with those in wildtype mice and $\mathrm{G} \alpha \mathrm{s}^{*}$ sacrificed from the home cage. Consistent with the fact that $\mathrm{G} \alpha \mathrm{s}^{*}$ does not affect cAMP levels in the amygdala (Kelly et al. 2007), Gas* does not significantly affect Arc expression within the amygdala. Consistent with findings in 


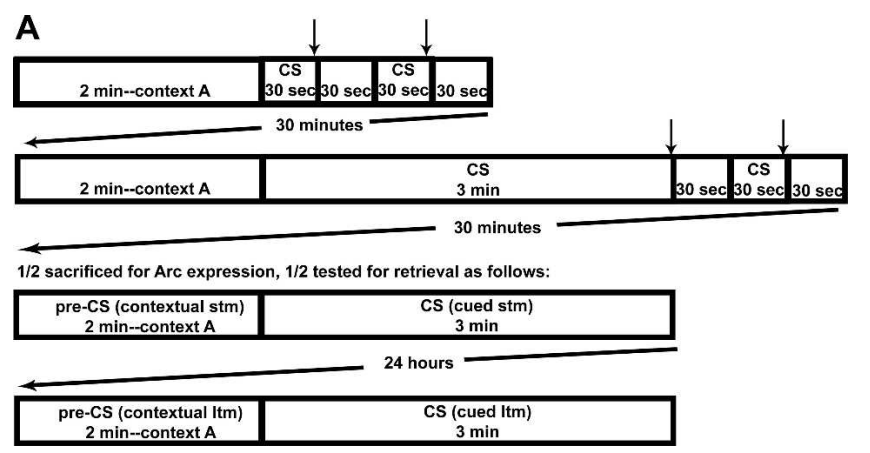

B

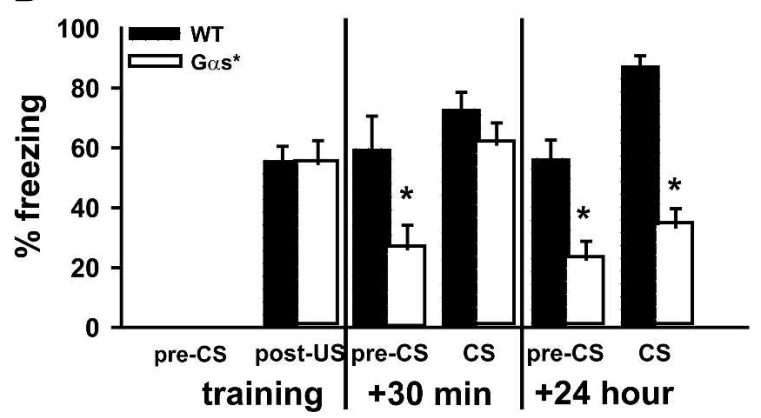

Figure 3. Following extended training, $G \alpha s^{*}$ mice show normal levels of freezing to the CS during the short-term but not long-term memory test. (A) Wild-type (WT, $n=5)$ and ${\mathrm{G} \alpha \mathrm{s}^{*}}^{*}$ transgenic mice $(n=7)$ were trained to associate a conditioned auditory stimulus (CS) with an unconditioned 1.5-mA footshock stimulus (US). Small vertical arrow indicates four presentations of a 2 -sec $1.5-\mathrm{mA}$ footshock. Both short-term $(+30$ $\mathrm{min}$ ) and long-term memory ( $+24 \mathrm{~h})$ for the training context and cue were assessed. (B) Across retrieval tests, G $\alpha s^{*}$ mice $(n=7)$ exhibit significantly lower levels of freezing to the training context relative to wild-type littermates $(n=5)$. In contrast, G $\alpha s^{*}$ mice show normal levels of freezing to the cue $30 \mathrm{~min}$, but not $24 \mathrm{~h}$, following training; ${ }^{*}$ post-hoc vs. WT, $P<0.01-0.001$.

Experiment 1, Arc mRNA expression does show a significant effect of genotype within cortical regions, with $\mathrm{G} \mathrm{s}^{*}$ mice exhibiting lower levels of expression across behavioral conditions in visual cortex $\left(F_{(1,19)}=18.93, P<0.001\right)$, parietal cortex $\left(F_{(1,19)}=13.07, P=0.002\right)$, somatosensory cortex $\left(F_{(1,19)}=10.48\right.$, $P=0.004)$, entorhinal cortex $\left(F_{(1,18)}=5.36, P<0.05\right)$, and orbital cortex $\left(F_{(1,20)}=4.41, P<0.05\right)$. There is no significant effect of genotype in $\mathrm{CA} 1, \mathrm{CA} 3$, or medial $\mathrm{CPu}$. There is, however, a significant effect of genotype in lateral $\mathrm{CPu}$, with $\mathrm{G} \alpha \mathrm{s}^{*}$ mice showing higher levels of Arc expression across training conditions $\left(F_{(1,20)}=13.14, P<0.001\right)$.

Not surprisingly, most regions show a dramatic effect of behavioral condition, with trained animals exhibiting significantly higher levels of Arc mRNA across genotypes in amygdala $\left(F_{(1,19)}=10.20, P=0.005\right)$, visual cortex $\left(F_{(1,19)}=9.05, P<0.01\right)$, parietal cortex $\left(F_{(1,19)}=19.90, P<0.001\right)$, somatosensory cortex $\left(F_{(1,19)}=20.73, P<0.001\right)$, entorhinal cortex $\left(F_{(1,18)}=5.10\right.$, $P<0.05)$, and orbital cortex $\left(F_{(1,20)}=8.18, P=0.01\right)$, as well as CA1 medial $\left(F_{(1,20)}=9.99, P=0.005\right)$, CA1 lateral $\left(F_{(1,20)}=7.10\right.$, $P=0.015)$, and CA3 $\left(F_{(1,20)}=10.01, P=0.005\right)$. There is no significant effect of training, however, on Arc mRNA levels of $\mathrm{CPu}$ (medial nor lateral). Of note, there are no significant interactions between genotype and behavioral condition in any region, suggesting that across amygdala, cortical, and hippocampal subregions, trained $\mathrm{G}_{\alpha \mathrm{S}^{*}}$ and trained wild-type mice show an equivalent increase in Arc mRNA relative to their respective home cage group.

\section{Discussion}

We show here that constitutive activation of the G-protein subunit $\mathrm{G} \alpha$ s within postnatal forebrain neurons results in a PKAdependent decrease in memory for fear conditioning along with PKA-dependent decreases in neuronal activity within the cortex, as mapped by Arc mRNA expression. Consistent with the PKAdependent deficits in memory and cortical Arc mRNA expression, we show that $G \alpha s^{*}$ triggers a compensatory up-regulation in the activity of a PDE family that is regulated by PKA, namely, PDE1. Together, these results elucidate the complexity of feedback and feedforward mechanisms at play within the cAMP cascade, emphasizing that care must be taken if cognitive enhancement is to be gained from augmentation of this signaling pathway.

\section{G $\alpha s^{*}$ triggers a compensatory up-regulation of cAMP hydrolysis by PDE 1}

One downstream consequence of $G \alpha s^{*}$ signaling appears to be a PKA-dependent up-regulation of cAMP PDE activity that occurs in the cortex and hippocampus but not in the striatum (Kelly et al. 2007). We show here that $\mathrm{G} \alpha \mathrm{s}^{*}$ mice show a significant increase in cAMP PDE1 activity and a trend toward increased cAMP PDE4 activity within the cortex. Interestingly, when PDE1 activity is inhibited, the remaining levels of cAMP PDE activity do not differ between transgenic and wild-type mice. This suggests that the increase in cAMP PDE1 activity measured here is largely responsible for the PKA-dependent increase in total cAMP PDE activity measured in cortex of $\mathrm{G} \alpha \mathrm{s}^{*}$ mice (Kelly et al. 2007).

It is important to acknowledge, however, that the inability to measure a significant change in PDE4 activity levels may reflect technical limitations as opposed to a lack of a biological effect. There are over 20 different PDE4 isoforms, and activity changes in a subset of these may not be detectable with current techniques that measure total PDE4 activity (i.e., all PDE4 isoforms inhibited by rolipram), particularly when analyzing an entire brain region of heterogeneous cell types. Given the ability of specific PDE4 isoforms to regulate localized cAMP levels (Mongillo et al. 2004; Terrin et al. 2006) and complex to other proteins within microdomains (see Houslay and Adams 2003), including the PKA-binding scaffold protein A-kinase anchoring protein (Tasken et al. 2001; Dodge-Kafka et al. 2005), changes in specific localized isoforms of PDE4 are likely to have a profound functional impact (Lynch et al. 2005). In fact, an up-regulation of PDE 4 activity in $\mathrm{G} \alpha \mathrm{s}^{*}$ mice would be consistent with the ability of rolipram, a PDE4 inhibitor, to rescue sensorimotor gating deficits in $\mathrm{G} \alpha \mathrm{s}^{*}$ mice (Kelly et al. 2007). Further, a co-up-regulation of PDE1 and PDE4 has been observed in thyroid adenomas expressing ${\mathrm{G} \alpha \mathrm{s}^{*}}^{*}$ (Persani et al. 2000), in cardiac tissue overexpressing AC8 - a downstream target of Gas (Georget et al. 2003) —and in brain following chronic electroconvulsive shock (Cho et al. 2000). Similarly, alterations in additional cAMP PDE families for which there are no selective tools available (e.g., PDE7) cannot be entirely ruled out.

The most parsimonious explanation as to why $\mathrm{G} \alpha \mathrm{s}^{*}$ induces a compensatory up-regulation in cAMP PDE activity in a brain region-specific manner relates to the fact that PDE families are expressed differentially across brain regions and even localize to different subcellular compartments (cf. Houslay and Adams 2003; Houslay et al. 2005; Lugnier 2006). Focusing on the PDE1 family, PDE1A appears to be expressed preferentially in the cortex and hippocampus, whereas PDE1B and PDE1C appear to be expressed preferentially in the striatum (Yan et al. 1994, 1996). As such, we would hypothesize that the increase in cortical cAMP PDE1 activity noted above is largely due to $\mathrm{GS}^{*}$ increasing activity of the PDE1A subtype, specifically. Since PDE1A is not expressed at high levels in the striatum, this compensatory path- 

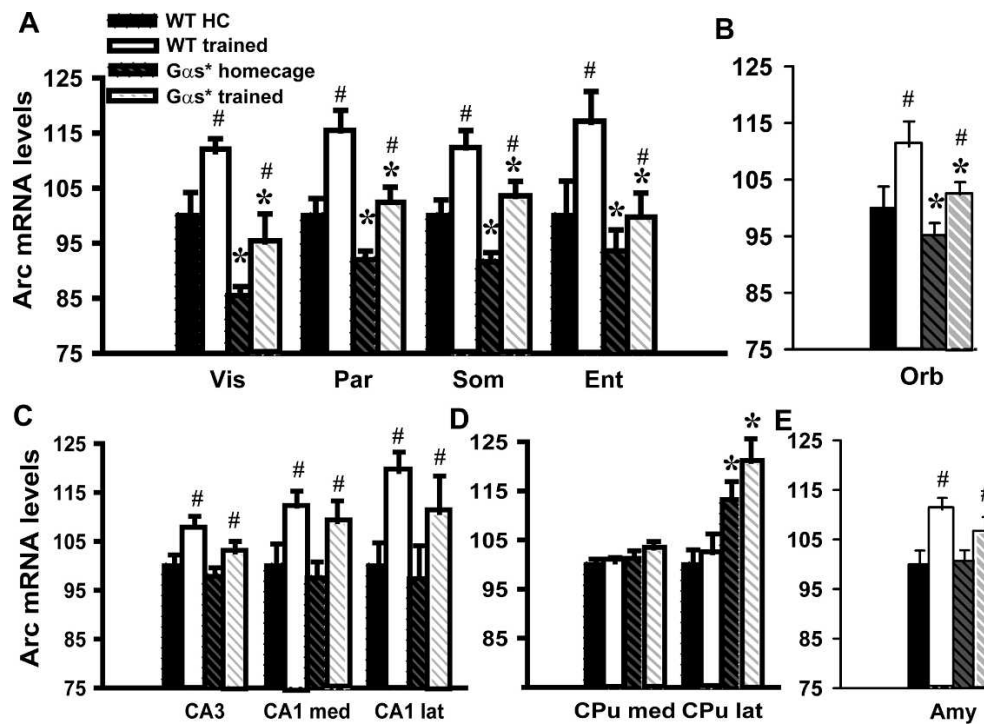

Figure 4. G $\alpha s^{*}$-induced decreases in cortical Arc mRNA persist following extended training with four CS US pairings. Arc mRNA levels (\% WT home cage) were measured in wild-type (WT) and $\mathrm{G} \alpha \mathrm{s}^{*}$ mice sacrificed 30 min following training with four CS-US pairings ( $n=6$ for each genotype). Arc levels in trained mice were compared to those found in animals sacrificed in parallel from the home cage (WT,

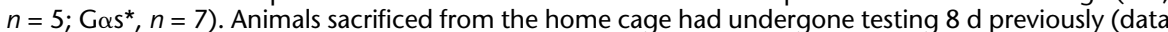
in Fig. 3; see Materials and Methods for further details). (A) In cortices surrounding the hippocampus and $(B)$ orbital cortex, training with four CS-US pairings significantly increases Arc mRNA levels across genotypes; however, Gas* mice still show significantly lower levels of Arc mRNA relative to wild-type littermates across behavioral conditions. (C) In the hippocampus, training with four CS-US pairings also increases $\operatorname{Arc}$ mRNA levels; however, there is no significant effect of genotype. (D) There is no significant effect of training nor genotype in medial caudate putamen ( $\mathrm{CPu}$ ); however, $\mathrm{G} \alpha \mathrm{s}^{*}$ mice show significantly higher levels of $\operatorname{Arc}$ across training conditions in lateral CPu. $(E)$ In the amygdala, training with four CS-US pairings significantly increases Arc expression in both wild-type and Gas* mice, with no significant difference between genotypes. (Abbreviations as in Fig. 2.) (*)Effect of genotype, $P<0.02-0.002 ;$ (\#) effect of training, $P<0.02$.

way is not likely to be activated, thus allowing cAMP levels to become significantly increased in this brain region in response to

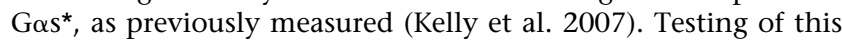
hypothesis remains for future experiments.

\section{G $\alpha s^{\star}$ mice show deficits in memory for fear conditioning}

In Experiment $1, \mathrm{G} \alpha \mathrm{s}^{*}$ mice show lower levels of freezing to a CS $30 \mathrm{~min}$ and $24 \mathrm{~h}$ following fear conditioning with one CS-US pairing, suggesting short-term and long-term memory deficits. Complicating this interpretation, however, is the fact that $\mathrm{G} \alpha \mathrm{s}^{*}$ mice also exhibit lower levels of pre-CS freezing in a novel context $24 \mathrm{~h}$ following conditioning. It could be suggested, then, that $\mathrm{G} \alpha \mathrm{s}^{*}$ causes a general decrease in freezing or even an inability to freeze, as opposed to a deficit in the consolidation or retrieval of fear memory. Inspection of the data, however, reveals that $\mathrm{G} \alpha \mathrm{S}^{*}$ mice show normal levels of freezing following the US in Experiment 1 as well as during the CS presentation of the short term memory test of Experiment 2. As such, the lower levels of freezing measured in $\mathrm{G} \alpha \mathrm{s}^{*}$ mice are more likely to reflect impairments in memory consolidation and/or retrieval.

What remains unclear is whether $G \alpha s^{*}$ mice have deficits in associative vs. nonassociative fear memory. It is important to first establish that the increase in pre-CS freezing observed in a novel context following fear conditioning (i.e., pre-CS freezing during retrieval - pre-CS freezing during training) is generally regarded as a conditioned (i.e., learned) response. This conditioned response is referred to as generalized fear and is well-established to occur in our background strain of C57Bl6/J mice (e.g., Balogh and Wehner 2003). The generalized fear response increases with increasing intensity of the US (Baldi et al. 2004), is modulated by the complexity of the training context (Moses et al. 2007), and is subject to the incubation effect (i.e., strengthens with time; Houston et al. 1999; Balogh and Wehner 2003). In this way, generalized fear shares many features in common with associative memory and may reflect associative memory for the US and events or features outside of the immediate shock context (e.g., being handled by experimenter and simply being removed from home cage, distal cues in training room, etc.; Houston et al. 1999). These similarities aside, generalized fear may instead reflect nonassociative learning (e.g., sensitization).

If one interprets the $\mathrm{G} \alpha \mathrm{s}^{*}$ data from Experiment 1 based on absolute levels of freezing or even difference scores (i.e., CS freezing - pre-CS freezing), one would suggest the $G \alpha s^{*}$-induced decreases in freezing to the CS reflect an impairment in associative memory for cued fear. Alternatively, if one interprets the $\mathrm{G}_{\alpha \mathrm{s}^{*}}$ data from Experiment 1 in terms of fold-changes (CS/pre-CS), one would suggest that $\mathrm{G}_{\mathrm{S}} \mathrm{s}^{*}$ mice have a deficit in nonassociative memory, as indicated by lower pre-CS freezing levels, but normal associative memory. It would be difficult, however, to accommodate in this latter interpretation the fact that $G \alpha \mathrm{S}^{*}$ mice show a significant decrease in CS freezing between short-term and long-term memory tests of Experiment 2 (in terms of absolute levels, $\mathrm{stm}-\mathrm{ltm}$, or $\mathrm{ltm} / \mathrm{stm})$, whereas controls do not. As such, we suggest $\mathrm{G} \alpha \mathrm{s}^{*}$ mice show not only a specific decrease in associative memory for the CS but also a decrease in conditioned generalized fear, both of which are rescued by co-expression of a dominant negative regulatory subunit of PKA.

\section{G $\alpha s^{*}$-induced deficits in associative memory are PKA-dependent}

Co-expression of $\mathrm{R}(\mathrm{AB})$, a dominant-negative regulatory subunit of PKA (Abel et al. 1997), fully rescues both short- and long-term memory impairments observed in $\mathrm{G} \alpha \mathrm{S}^{*}$ mice following fear conditioning. Surprisingly, the $\mathrm{R}(\mathrm{AB})$-only mice exhibited improved short-term-but not long-term-memory relative to wild-type mice under the current training protocol. This stands in contrast to previously published training protocols employing lower footshock intensities in which $\mathrm{R}(\mathrm{AB})$ mice show no differences in cued fear (Abel et al. 1997). The basis for such a select effect of the $\mathrm{R}(\mathrm{AB})$ transgene is unclear and will be of interest to future studies. The fact that expression of $\mathrm{R}(\mathrm{AB})$ alone does not alter longterm memory for cued fear conditioning suggests that $\mathrm{R}(\mathrm{AB})$ elicits its effects within $\mathrm{G} \alpha \mathrm{s}^{*}$ mice by specifically interfering with elevated, as opposed to normal, levels of PKA activity. Interestingly, it appears that increasing the amount of training to four CS-US pairings is sufficient to overcome the PKA-dependent effects of ${\mathrm{G} \alpha \mathrm{S}^{*}}^{*}$ on short-term, but not long-term, fear memory.

$\mathrm{G} \alpha \mathrm{s}^{*}$ may cause deficits in fear conditioning by disrupting signaling through dopamine D1 or norepinephrine $\beta_{1}$ receptors, both of which couple to G $\alpha$ s and are key to fear conditioning 
(Murchison et al. 2004; Pezze and Feldon 2004). Alternatively, given that augmentation of cAMP signaling by rolipram has been shown to improve cued fear conditioning (Monti et al. 2006), it is possible that $G \alpha \mathrm{S}^{*}$ mice exhibit deficits in fear conditioning due to the PKA-dependent decreases in cAMP measured in cortex and hippocampus of these animals (Kelly et al. 2007). Since inhibition of PKA is not sufficient to impair cued fear conditioning, and in fact rescues the $G \alpha s^{*}$-induced deficits, the effect of decreased cAMP signaling on cued fear conditioning would likely be mediated through decreased signaling of other downstream targets of cAMP, such as Epac or cyclic nucleotide-gated channels (Kopperud et al. 2003). It will be of interest to future studies to determine if the contextual and spatial memory deficits exhibited by $\mathrm{G}_{\alpha \mathrm{s}^{*}}$ mice (Bourtchouladze et al. 2006) are also reversed by PKA inhibition.

\section{G $\alpha s^{*}$ mice show PKA-dependent reductions in cortical neuronal activity as indicated by decreased Arc mRNA levels}

Although the amygdala is a brain region central to fear conditioning (Phillips and LeDoux 1992), other brain regions have been implicated as playing a role in this behavior, including the cortex (e.g., Schenberg et al. 2005; Boatman and Kim 2006) and striatum (Ferreira et al. 2003; White and Salinas 2003). Given that $\mathrm{G} \alpha \mathrm{s}^{*}$ mice show normal cAMP levels in the amygdala (Kelly et al. 2007), we attempted to identify what other brain region(s)

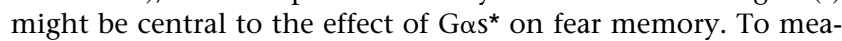
sure neuronal activity within various brain regions, we mapped mRNA levels of the activity-regulated immediate-early gene Arc. Consistent with effects of $G \alpha s^{*}$ on cAMP levels, G $\alpha s^{*}$ mice show normal Arc expression in the amygdala, both basally and following training in the extended fear-conditioning paradigm. In contrast, G $\alpha \mathrm{s}^{*}$ mice show PKA-dependent decreases in basal levels of $\operatorname{Arc}$ mRNA within the cortex that are reflected in levels observed following extended training with four CS-US pairings. That is, trained $\mathrm{G}_{\alpha \mathrm{S}^{*}}$ mice show lower levels of cortical Arc mRNA expression relative to trained WT mice due to a lower starting level of expression as opposed to an inability to induce Arc mRNA from this lower baseline. Thus, it appears that changes in neuronal activity specifically within the cortex are related to the fear memory deficits measured in $\mathrm{G}_{\alpha} \mathrm{s}^{*}$ transgenic mice.

The changes in Arc expression noted above may not only elucidate the neuronal circuitry but also the molecular cascade mediating the learning and memory impairments observed in $\mathrm{G} \alpha \mathrm{s}^{*}$ mice. Arc localizes to post-synaptic densities (Husi et al. 2000) and is necessary for the maintenance of long-term changes in synaptic plasticity and memory (Guzowski et al. 2000; Plath et al. 2006). Further, increases in Arc mRNA and/or protein are associated with several types of memory formation, including cued fear conditioning (Monti et al. 2006), contextual fear conditioning (Huff et al. 2006); operant conditioning (Kelly and Deadwyler 2002, 2003), spatial memory (Guzowski et al. 2000, 2001), and inhibitory avoidance (McIntyre et al. 2005). The fact that genetically deleting Arc is sufficient to induce cued fear-conditioning impairments (Plath et al. 2006) suggests that the lower basal levels of cortical Arc expression found in $\mathrm{G}_{\alpha \mathrm{s}^{*}}$ mice may contribute to the observed long-term memory deficits. It is important to acknowledge, however, that experiments presented here do not establish a cause-and-effect relationship between the observed changes in Arc levels and memory impairments.

Interestingly, $\mathrm{R}(\mathrm{AB})$ mice with inhibited PKA activity (Abel et al. 1997) show no decreases in Arc expression in any region. This finding is consistent with the fact that $\mathrm{R}(\mathrm{AB})$ mice show no deficit in the cued fear-conditioning task. These results stand in contrast, however, to those of Waltereit et al. (2001) showing that cAMP induces Arc mRNA in a PKA-dependent manner in cultured hippocampal neurons. In this context, it is also of note that ${\mathrm{G} \alpha \mathrm{S}^{*}}^{*}$ increases $\operatorname{Arc}$ mRNA levels in lateral but not medial caudate putamen $(\mathrm{CPu})$, raising the possibility that cAMP induction and Arc expression are disconnected in medial $\mathrm{CPu}$. Together, these results suggest a differential regulation of Arc expression in vivo vs. in vitro.

In conclusion, constitutive activation of the cAMP cascade through $\mathrm{G} \alpha \mathrm{s}^{*}$ results in complex, region-specific compensatory changes that ultimately reduce signaling through this pathway and cause behavioral deficits. Our results presented here and elsewhere (Bourtchouladze et al. 2006; Kelly et al. 2007) suggest that chronically stimulating targets upstream of cAMP may not be a therapeutically viable approach to the treatment of neurocognitive deficits.

\section{Materials and Methods}

\section{Subjects}

As previously described (Kelly et al. 2007), transgenic mice were bred and group-housed in breeding colonies at the University of Pennsylvania in a hemizygous state on a C57BL/6J background (N13-N16). In experiments examining the effect of genetic inhibition of PKA activity, hemizygous $\mathrm{Gs}^{*}$ transgenic mice were mated to hemizygous $\mathrm{R}(\mathrm{AB})$ transgenic mice, and all offspring were compared (wild-type, $\mathrm{G} \alpha \mathrm{s}^{*}$ transgenic, $\mathrm{R}(\mathrm{AB})$ transgenic, $\mathrm{G}_{\alpha \mathrm{s}^{*}}$ and $\mathrm{R}(\mathrm{AB})$ bi-transgenic). In experiments comparing $\mathrm{G} \alpha \mathrm{s}^{*}$ and wild-type mice only, hemizygous ${\mathrm{G} \alpha \mathrm{s}^{*}}^{*}$ transgenic mice were mated to C57BL/6J mice and sex-matched littermates were compared. G $\alpha \mathrm{s}^{*}$ transgenic mice express an isoform of the G-protein subunit $G \alpha$ s that is constitutively active due to a point mutation (Q227L) that prevents hydrolysis of bound GTP. As previously described (Kelly et al. 2007), expression of $\mathrm{G} \mathrm{s}^{*}$ significantly increases basal adenylyl cyclase activity. $\mathrm{R}(\mathrm{AB})$ transgenic mice express a dominant-negative regulatory subunit for PKA that inhibits PKA activity (Abel et al. 1997). Expression of both the G $\alpha s^{*}$ and $\mathrm{R}(\mathrm{AB})$ transgenes are restricted to postnatal forebrain neurons through the use of the CaMKII $\alpha$ promoter. As previously shown (Abel et al. 1997; Kelly et al. 2007), Gos* and R(AB) are expressed throughout cortex, hippocampus, striatum, and amygdala. Using a transgene-specific probe, animals were genotyped by Southern blot (Abel et al. 1997); however, all experimenters were blind to genotype. See figure legends for specific number of subjects in each group for behavioral and molecular experiments.

\section{PDE assays}

Animals were sacrificed by cervical dislocation, and cortical regions surrounding the hippocampus from the right hemisphere were immediately dissected and placed on dry ice. PDE4 and PDE1 activity was measured as previously described (Spence et al. 1995; MacKenzie et al. 2002), using a standard concentration of cAMP $(1 \mu \mathrm{m})$, rolipram $(10 \mu \mathrm{m}$ to determine the rolipraminhibited PDE4 activity), and vinpocetine (100 $\mu \mathrm{m}$ to determine the vinpocetine-inhibited PDE1 activity). We also examined PDE2 activity with EHNA and PDE3 activity with cilostamide; however, we did not detect reliable inhibition of cAMP PDE activity in cortex using either inhibitor (data not shown).

\section{Fear conditioning}

\section{Experiment 1}

Mice were trained to associate a $1.5-\mathrm{mA}$ footshock with presentation of an auditory cue (white noise; Fig. 1A), as previously described (Lattal and Abel 2001). Mice were handled for 2 min on days 1-3. On day 4, mice underwent training for cued fear conditioning. For training, mice were placed in the experimental chamber for a total of $3 \mathrm{~min} ; 2$ min into the session the cue was played for $30 \mathrm{sec}$, during the last $2 \mathrm{sec}$ of which the footshock was administered. At the end of the 3-min training session, mice were returned to their home cages. For testing short-term memory 
(stm) 30 min following training, mice were placed into a different experimental chamber for a total of $5 \mathrm{~min}$ with the cue playing the last $3 \mathrm{~min}$ of the session. To test for long-term memory (ltm), mice were retested $24 \mathrm{~h}$ later.

\section{Experiment 2}

In an attempt to improve performance in $\mathrm{G} \alpha \mathrm{s}^{*}$ mice, subjects were given extended training and provided both contextual and auditory cues during the retrieval tests (Fig. 3A). Training progressed as above except that, instead of returning to the home cage at the end of the initial 3-min training session, mice were exposed to a second CS-US pairing followed by an additional $30 \mathrm{sec}$ in the chamber before being returned to the home cage (total session length: $4 \mathrm{~min}$ ). After $30 \mathrm{~min}$, mice were placed back into the same experimental chamber. Mice were placed in the chamber for $2 \mathrm{~min}$, after which time a 3-min cue played with a co-terminating 2-sec long 1.5-mA footshock. As above, the mice remained in the cage an additional $30 \mathrm{sec}$ and then were presented with the second CS/US pairing. After a final $30 \mathrm{sec}$ in the chamber, mice were returned to the home cage (total session length: $6.5 \mathrm{~min}$ ); 30 min following the second training block, mice were again returned to the same experimental chamber for $5 \mathrm{~min}$ of testing stm for contextual ( $2 \mathrm{~min}$ ) and cued fear ( $3 \mathrm{~min}$ ). Twenty-four hours later, mice were again tested in the same manner to test for $\mathrm{ltm}$. With this design (i.e., introducing a 30-min delay between the first and second training blocks), we were able to assess short-term memory for the first training block (two shocks) and found that two CS-US pairings were not sufficient to rescue levels of freezing in the transgenic mice (data not shown). In both experiments, the footshock elicited squeaking and jumping from all mice. Furthermore, freezing - a natural fear response characterized by the complete lack of movement-was measured during each training and testing epoch (Fanselow 1980). Throughout training and testing, mice were observed once every $5 \mathrm{sec}$, and the percentage of these observations in which mice froze was calculated for each epoch.

\section{In situ hybridization}

For each of the two Arc experiments, the first measuring PKAdependent changes and the second measuring training-induced changes, two groups of animals were sacrificed on separate days by cervical dislocation. In the first study examining the PKAdependent changes in basal expression, the first group of animals were naive to fear conditioning (animals used in cAMP analyses reported in Kelly et al. 2007), whereas the second group of the animals were those animals tested in the first fear-conditioning experiment. This second group of mice was sacrificed $8 \mathrm{~d}$ following behavioral testing, in an attempt to measure basal Arc mRNA levels. There was no difference in expression changes between the first and second group of animals, verifying that $8 \mathrm{~d}$ was a sufficient interval of time to allow levels of $\operatorname{Arc}$ mRNA expression to return to baseline. For Experiment 2, animals were sacrificed in parallel 30 min following training with four CS-US pairings (as described above) or from the home cage. Animals in the home cage condition had undergone behavioral testing $8 \mathrm{~d}$ previous to the day of sacrifice (behavioral data represented in Fig. 3). For both experiments, brains were harvested fresh, hemisected sagittally, immediately frozen in $-30^{\circ} \mathrm{C}$ isopentane, and stored at $-80^{\circ} \mathrm{C}$ until time of cryosectioning. Brains were mounted in blocks of four, and 20 - $\mu \mathrm{m}$ sagittal sections (containing all four brains) were thaw mounted on slides. Post-fixing of tissue and autoradiographic in situ hybridization were conducted as previously described (Kelly and Deadwyler 2002, 2003), using an oligonucleotide probe for mouse Arc: GCAGCTTCAGGAGAAGAG AGGATGGTGCTGGTGCTGG. Relative optical densities (r.o.d.) of three sections per animal were quantified using NIH Image. Measures were taken from all transgene expressing areas and included visual cortex, parietal cortex, somatosensory cortex, orbital cortex, CA1 (medial), CA3, and striatum $(\sim 1.44-1.92 \mathrm{~mm}$ lateral from Bregma), as well as amygdala, CA1 (lateral), and entorhinal cortex ( $2.88-3.36 \mathrm{~mm}$ lateral from Bregma). In experiment $1, \operatorname{Arc}$ expression was not measurable in the amygdala be- cause levels were below the threshold of reliable detection by autoradiography. In experiment 2 , however, we were able to measure optical densities for the amygdala as a whole (autoradiographs do not provide sufficient resolution to define subregions) taking one circularly shaped sample that was similarly sized and positioned (relative to striatum and hippocampus) across sections.

\section{Data analysis}

All data was collected by experimenters blind to genotype and analyzed using SigmaStat 2.03 (Systat, San Jose, CA). For the PDE and Arc studies, different groups of animals were sacrificed and processed on different days. Therefore, raw data for each brain region were normalized as a percentage of the control group (home cage wild-type mice) to account for any confounding effects due to day of sacrifice or efficiency of probe incorporation (Kelly and Deadwyler 2003; Kelly et al. 2007). Normalized data were then analyzed for effects of genotype by $t$-test (PDE1 and PDE4), ANOVA (Arc in striatum and orbital cortex), or repeatedmeasures ANOVA (Arc in cortical regions surrounding the hippocampus and hippocampal subregions). Analyses of regional Arc levels were carried out so as to correspond to the regions previously dissected in the characterization of cAMP levels and PDE activity in these mice (striatum, frontal cortex, temporal cortex, and hippocampus; Kelly et al. 2007). For fear-conditioning experiments, the percent freezing in each training epoch (basal and post-US) was analyzed for effect of genotype by analysis of variance (ANOVA) and the percent freezing in each testing epoch (pre-CS and CS) was analyzed for effect of genotype and retrieval test (stm vs. ltm) by repeated-measures ANOVA (RM ANOVA). All post-hoc testing was conducted by Student-Newman-Keuls range statistics. Statistical outliers (greater than two standard deviations from the mean) were dropped from analyses. Statistical significance is determined at $P<0.05$. All data are expressed as mean \pm SEM.

\section{Acknowledgments}

We thank Dr. John Guzowski for technical instruction on brainmounting techniques. We also acknowledge funding support from the Merck, Whitehall, and Packard Foundations as well as NIMH (R01 MH60244, NIA R01 AG18199, and P50 MH 6404501), Project 3 to T.A. (R. Gur, Conte Center P.I.), who is a John Merck Scholar and a David and Lucile Packard Foundation Fellow. Additional support includes NIMH K08 MH067091 to S.J.K., NIAA AA09000 to G.W., and a Tourette's Syndrome Association Fellowship to M.P.K., who was also supported by NIMH T32 MH019112 (R. Gur, P.I.). Finally, M.D.H. thanks the Medical Research Council (United Kingdom) (G8604010) and the European Union (QLK3-CT-2002-02149) for funding.

\section{References}

Abel, T., Nguyen, P.V., Barad, M., Deuel, T.A., Kandel, E.R., and Bourtchouladze, R. 1997. Genetic demonstration of a role for PKA in the late phase of LTP and in hippocampus-based long-term memory. Cell 88: 615-626.

Barad, M., Bourtchouladze, R., Winder, D.G., Golan, H., and Kandel, E. 1998. Rolipram, a type IV-specific phosphodiesterase inhibitor, facilitates the establishment of long-lasting long-term potentiation and improves memory. Proc. Natl. Acad. Sci. 95: 15020-15025.

Barco, A., Pittenger, C., and Kandel, E.R. 2003. CREB, memory enhancement and the treatment of memory disorders: Promises, pitfalls and prospects. Expert Opin. Ther. Targets 7: 101-114.

Baldi, E., Lorenzini, C., and Bucherelli, C. 2004. Footshock intensity and generalization in contextual and auditory-cued fear conditioning in the rat. Neurobiol. Learn. Mem. 81: 162-166.

Balogh, S.A. and Wehner, J.M. 2003. Inbred mouse strain differences in the establishment of long-term fear memory. Behav. Brain Res. 140: $97-106$.

Beavo, J.A. and Brunton, L.L. 2002. Cyclic nucleotide research-Still expanding after half a century. Nat. Rev. Mol. Cell Biol. 3: 710-718.

Blum, S., Moore, A.N., Adams, F., and Dash, P.K. 1999. A mitogen-activated protein kinase cascade in the CA1/CA2 subfield of the dorsal hippocampus is essential for long-term spatial memory. J. Neurosci. 19: 3535-3544. 
Boatman, J.A. and Kim, J.J. 2006. A thalamo-cortico-amygdala pathway mediates auditory fear conditioning in the intact brain. Eur. J. Neurosci. 24: 894-900.

Bourtchouladze, R., Lidge, R., Catapano, R., Stanley, J., Gossweiler, S., Romashko, D., Scott, R., and Tully, T. 2003. A mouse model of Rubinstein-Taybi syndrome: Defective long-term memory is ameliorated by inhibitors of phosphodiesterase 4. Proc. Natl. Acad. Sci. 100: 10518-10522.

Bourtchouladze, R., Patterson, S.L., Kelly, M.P., Kreibich, A., Kandel, E.R., and Abel, T. 2006. Chronically increased Gs $\alpha$ signaling disrupts associative and spatial learning. Learn. Mem. 13: 745-752.

Burgess, N., Maguire, E.A., and O'Keefe, J. 2002. The human hippocampus and spatial and episodic memory. Neuron 35: 625-641.

Cho, C.H., Cho, D.H., Seo, M.R., and Juhnn, Y.S. 2000. Differential changes in the expression of cyclic nucleotide phosphodiesterase isoforms in rat brains by chronic treatment with electroconvulsive shock. Exp. Mol. Med. 32: 110-114.

Connolly, J.B., Roberts, I.J., Armstrong, J.D., Kaiser, K., Forte, M., Tully, T., and O'Kane, C.J. 1996. Associative learning disrupted by impaired Gs signaling in Drosophila mushroom bodies. Science 274: $2104-2107$.

Dodge-Kafka, K.L., Soughayer, J., Pare, G.C., Carlisle Michel, J.J., Langeberg, L.K., Kapiloff, M.S., and Scott, J.D. 2005. The protein kinase A anchoring protein mAKAP coordinates two integrated cAMP effector pathways. Nature 437: 574-578.

Fanselow, M.S. 1980. Conditioned and unconditional components of post-shock freezing. Pavlov. J. Biol. Sci. 15: 177-182.

Ferreira, T.L., Moreira, K.M., Ikeda, D.C., Bueno, O.F., and Oliveira, M.G. 2003. Effects of dorsal striatum lesions in tone fear conditioning and contextual fear conditioning. Brain Res. 987: 17-24.

Georget, M., Mateo, P., Vandecasteele, G., Lipskaia, L., Defer, N., Hanoune, J., Hoerter, J., Lugnier, C., and Fischmeister, R. 2003. Cyclic AMP compartmentation due to increased cAMP-phosphodiesterase activity in transgenic mice with a cardiac-directed expression of the human adenylyl cyclase type 8 (AC8). FASEB J. 17: 1380-1391.

Gusev, P.A., Cui, C., Alkon, D.L., and Gubin, A.N. 2005. Topography of Arc/Arg3.1 mRNA expression in the dorsal and ventral hippocampus induced by recent and remote spatial memory recall: Dissociation of CA3 and CA1 activation. J. Neurosci. 25: 9384-9397.

Guzowski, J.F., McNaughton, B.L., Barnes, C.A., and Worley, P.F. 1999. Environment-specific expression of the immediate-early gene Arc in hippocampal neuronal ensembles. Nat. Neurosci. 2: 1120-1124.

Guzowski, J.F., Lyford, G.L., Stevenson, G.D., Houston, F.P., McGaugh, J.L., Worley, P.F., and Barnes, C.A. 2000. Inhibition of activity-dependent arc protein expression in the rat hippocampus impairs the maintenance of long-term potentiation and the consolidation of long-term memory. J. Neurosci. 20: 3993-4001.

Guzowski, J.F., Setlow, B., Wagner, E.K., and McGaugh, J.L. 2001. Experience-dependent gene expression in the rat hippocampus after spatial learning: A comparison of the immediate-early genes Arc, c-fos, and zif268. J. Neurosci. 21: 5089-5098.

Hicks, J.K., Bahn, Y.S., and Heitman, J. 2005. Pde1 phosphodiesterase modulates cyclic AMP levels through a protein kinase A-mediated negative feedback loop in Cryptococcus neoformans. Eukaryot. Cell 4: 1971-1981.

Houslay, M.D. and Adams, D.R. 2003. PDE4 cAMP phosphodiesterases: Modular enzymes that orchestrate signalling cross-talk, desensitization and compartmentalization. Biochem. J. 370: 1-18.

Houslay, M.D., Schafer, P., and Zhang, K.Y. 2005. Keynote review: Phosphodiesterase- 4 as a therapeutic target. Drug Discov. Today 10: $1503-1519$.

Houston, F.P., Stevenson, G.D., McNaughton, B.L., and Barnes, C.A. 1999. Effects of age on the generalization and incubation of memory in the F344 rat. Learn. Mem. 6: 111-119.

Huff, N.C., Frank, M., Wright-Hardesty, K., Sprunger, D., Matus-Amat, P., Higgins, E., and Rudy, J.W. 2006. Amygdala regulation of immediate-early gene expression in the hippocampus induced by contextual fear conditioning. J. Neurosci. 26: 1616-1623.

Husi, H., Ward, M.A., Choudhary, J.S., Blackstock, W.P., and Grant, S.G. 2000. Proteomic analysis of NMDA receptor-adhesion protein signaling complexes. Nat. Neurosci. 3: 661-669.

Kelly, M.P. and Deadwyler, S.A. 2002. Acquisition of a novel behavior induces higher levels of Arc mRNA than does overtrained performance. Neuroscience 110: 617-626.

Kelly, M.P. and Deadwyler, S.A. 2003. Experience-dependent regulation of the immediate-early gene arc differs across brain regions. $J$. Neurosci. 23: 6443-6451.

Kelly, M.P., Isiegas, C., Cheung, Y.F., Tokarczyk, J., Yang, X., Esposito, M.F., Rapoport, D.A., Fabian, S.A., Siegel, S.J., Wand, G., et al. 2007. Constitutive activation of Gas within forebrain neurons causes deficits in sensorimotor gating because of PKA-dependent decreases in cAMP. Neuropsychopharmacology 32: 577-588.

Kopperud, R., Krakstad, C., Selheim, F., and Doskeland, S.O. 2003. cAMP effector mechanisms. Novel twists for an 'old' signaling system. FEBS Lett. 546: 121-126.

Lattal, K.M. and Abel, T. 2001. An immediate-shock freezing deficit with discrete cues: A possible role for unconditioned stimulus processing mechanisms. J. Exp. Psychol. Anim. Behav. Process. 27: 394-406.

Link, W., Konietzko, U., Kauselmann, G., Krug, M., Schwanke, B., Frey, U., and Kuhl, D. 1995. Somatodendritic expression of an immediate early gene is regulated by synaptic activity. Proc. Natl. Acad. Sci. 92: $5734-5738$

Livingstone, M.S., Sziber, P.P., and Quinn, W.G. 1984. Loss of calcium/calmodulin responsiveness in adenylate cyclase of rutabaga, a Drosophila learning mutant. Cell 37: 205-215.

Lugnier, C. 2006. Cyclic nucleotide phosphodiesterase (PDE) superfamily: A new target for the development of specific therapeutic agents. Pharmacol. Ther. 109: 366-398.

Lyford, G.L., Yamagata, K., Kaufmann, W.E., Barnes, C.A., Sanders, L.K., Copeland, N.G., Gilbert, D.J., Jenkins, N.A., Lanahan, A.A., and Worley, P.F. 1995. Arc, a growth factor and activity-regulated gene, encodes a novel cytoskeleton-associated protein that is enriched in neuronal dendrites. Neuron 14: 433-445.

Lynch, M.J., Baillie, G.S., Mohamed, A., Li, X., Maisonneuve, C., Klussmann, E., van Heeke, G., and Houslay, M.D. 2005. RNA silencing identifies PDE4D5 as the functionally relevant cAMP phosphodiesterase interacting with $\beta$-arrestin to control the protein kinase A/AKAP79-mediated switching of the $\beta_{2}$-adrenergic receptor to activation of ERK in HEK293B2 cells. J. Biol. Chem. 280: 3317833189 .

Ma, P., Wera, S., Van Dijck, P., and Thevelein, J.M. 1999. The PDE1-encoded low-affinity phosphodiesterase in the yeast Saccharomyces cerevisiae has a specific function in controlling agonist-induced cAMP signaling. Mol. Biol. Cell 10: 91-104.

MacKenzie, S.J., Baillie, G.S., McPhee, I., MacKenzie, C., Seamons, R., McSorley, T., Millen, J., Beard, M.B., van Heeke, G., and Houslay, M.D. 2002. Long PDE4 cAMP specific phosphodiesterases are activated by protein kinase A-mediated phosphorylation of a single serine residue in upstream conserved region 1 (UCR1). Br. J. Pharmacol. 136: 421-433.

McIntyre, C.K., Miyashita, T., Setlow, B., Marjon, K.D., Steward, O., Guzowski, J.F., and McGaugh, J.L. 2005. Memory-influencing intra-basolateral amygdala drug infusions modulate expression of Arc protein in the hippocampus. Proc. Natl. Acad. Sci. 102: 1071810723

Mongillo, M., McSorley, T., Evellin, S., Sood, A., Lissandron, V., Terrin, A., Huston, E., Hannawacker, A., Lohse, M.J., Pozzan, T., et al. 2004. Fluorescence resonance energy transfer-based analysis of cAMP dynamics in live neonatal rat cardiac myocytes reveals distinct functions of compartmentalized phosphodiesterases. Circ. Res. 95: $67-75$.

Monti, B., Berteotti, C., and Contestabile, A. 2006. Subchronic rolipram delivery activates hippocampal CREB and Arc, enhances retention and slows down extinction of conditioned fear. Neuropsychopharmacology 31: 278-286.

Morris, R.G., Schenk, F., Tweedie, F., and Jarrad, L.E. 1990. Ibotenate lesions of hippocampus and/or subiculum: Dissociating components of allocentric spatial learning. Eur. I. Neurosci. 2: 1016-1028.

Moses, S.N., Winocur, G., Ryan, J.D., and Moscovitch, M. 2007. Environmental complexity affects contextual fear conditioning following hippocampal lesions in rats. Hippocampus 17: 333-337.

Murchison, C.F., Zhang, X.Y., Zhang, W.P., Ouyang, M., Lee, A., and Thomas, S.A. 2004. A distinct role for norepinephrine in memory retrieval. Cell 117: 131-143.

Murdoch, H., Mackie, S., Collins, D.M., Hill, E.V., Bolger, G.B., Klussmann, E., Porteous, D.J., Millar, J.K., and Houslay, M.D. 2007. Isoform-selective susceptibility of DISC1/phosphodiesterase- 4 complexes to dissociation by elevated intracellular cAMP levels. I. Neurosci. 27: 9513-9524.

Persani, L., Lania, A., Alberti, L., Romoli, R., Mantovani, G., Filetti, S., Spada, A., and Conti, M. 2000. Induction of specific phosphodiesterase isoforms by constitutive activation of the cAMP pathway in autonomous thyroid adenomas. J. Clin. Endocrinol. Metab. 85: 2872-2878.

Pezze, M.A. and Feldon, J. 2004. Mesolimbic dopaminergic pathways in fear conditioning. Prog. Neurobiol. 74: 301-320.

Phillips, R.G. and LeDoux, J.E. 1992. Differential contribution of amygdala and hippocampus to cued and contextual fear conditioning. Behav. Neurosci. 106: 274-285.

Pineda, V.V., Athos, J., Wang, H., Celver, J., Ippolito, D., Boulay, G., Birnbaumer, L., and Storm, D.R. 2004. Removal of $\mathrm{G}_{\mathrm{i} \alpha 1}$ constraints on adenylyl cyclase in the hippocampus enhances LTP and impairs memory formation. Neuron 41: 153-163. 
Plath, N., Ohana, O., Dammermann, B., Errington, M.L., Schmitz, D. Gross, C., Mao, X., Engelsberg, A., Mahlke, C., Welzl, H., et al. 2006. Arc/Arg3.1 is essential for the consolidation of synaptic plasticity and memories. Neuron 52: 437-444.

Ramos, B.P., Birnbaum, S.G., Lindenmayer, I., Newton, S.S., Duman, R.S., and Arnsten, A.F. 2003. Dysregulation of protein kinase a signaling in the aged prefrontal cortex: New strategy for treating age-related cognitive decline. Neuron 40: 835-845.

Schenberg, E.E., Soares, J.C., and Oliveira, M.G. 2005. Effects of pre- or post-training entorhinal cortex AP5 injection on fear conditioning. Physiol. Behav. 86: 508-515.

Sharma, R.K. and Wang, J.H. 1986. Calmodulin and $\mathrm{Ca}^{2+}$-dependent phosphorylation and dephosphorylation of $63-\mathrm{kDa}$

subunit-containing bovine brain calmodulin-stimulated cyclic nucleotide phosphodiesterase isozyme. J. Biol. Chem. 261: 13221328.

Spence, S., Rena, G., Sweeney, G., and Houslay, M.D. 1995. Induction of $\mathrm{Ca}^{2+} /$ calmodulin-stimulated cyclic AMP phosphodiesterase (PDE1) activity in Chinese hamster ovary cells $(\mathrm{CHO})$ by phorbol 12-myristate 13-acetate and by the selective overexpression of protein kinase C isoforms. Biochem. J. 310: 975-982.

Tasken, K.A., Collas, P., Kemmner, W.A., Witczak, O., and Conti, M. 2001. Phosphodiesterase 4D and protein kinase a type II constitute a signaling unit in the centrosomal area. J. Biol. Chem. 276: 21999_ 22002.

Temple, M.D., Worley, P.F., and Steward, O. 2003. Visualizing changes in circuit activity resulting from denervation and reinnervation using immediate early gene expression. J. Neurosci. 23: 2779-2788.

Terrin, A., Di Benedetto, G., Pertegato, V., Cheung, Y.F., Baillie, G., Lynch, M.J., Elvassore, N., Prinz, A., Herberg, F.W., Houslay, M.D., et al. 2006. PGE 1 stimulation of HEK293 cells generates multiple contiguous domains with different [cAMP]: Role of compartmentalized phosphodiesterases. J. Cell Biol. 175: 441-451.

Vicini, E. and Conti, M. 1997. Characterization of an intronic promoter of a cyclic adenosine $3^{\prime}, 5^{\prime}$-monophosphate (cAMP)-specific phosphodiesterase gene that confers hormone and cAMP inducibility. Mol. Endocrinol. 11: 839-850.
Waltereit, R., Dammermann, B., Wulff, P., Scafidi, J., Staubli, U., Kauselmann, G., Bundman, M., and Kuhl, D. 2001. Arg3.1/Arc mRNA induction by $\mathrm{Ca}^{2+}$ and cAMP requires protein kinase $\mathrm{A}$ and mitogen-activated protein kinase/extracellular regulated kinase activation. J. Neurosci. 21: 5484-5493.

Wang, H., Ferguson, G.D., Pineda, V.V., Cundiff, P.E., and Storm, D.R. 2004. Overexpression of type- 1 adenylyl cyclase in mouse forebrain enhances recognition memory and LTP. Nat. Neurosci. 7: 635-642.

White, N.M. and Salinas, J.A. 2003. Mnemonic functions of dorsal striatum and hippocampus in aversive conditioning. Behav. Brain Res. 142: 99-107.

Wong, S.T., Athos, J., Figueroa, X.A., Pineda, V.V., Schaefer, M.L., Chavkin, C.C., Muglia, L.J., and Storm, D.R. 1999.

Calcium-stimulated adenylyl cyclase activity is critical for hippocampus-dependent long-term memory and late phase LTP. Neuron 23: 787-798.

Yan, C., Bentley, J.K., Sonnenburg, W.K., and Beavo, J.A. 1994. Differential expression of the $61 \mathrm{kDa}$ and $63 \mathrm{kDa}$ calmodulin-dependent phosphodiesterases in the mouse brain. J. Neurosci. 14: 973-984.

Yan, C., Zhao, A.Z., Bentley, J.K., and Beavo, J.A. 1996. The calmodulin-dependent phosphodiesterase gene PDE1C encodes several functionally different splice variants in a tissue-specific manner. J. Biol. Chem. 271: 25699-25706.

Zhang, H.T., Crissman, A.M., Dorairaj, N.R., Chandler, L.J., and O'Donnell, J.M. 2000. Inhibition of cyclic AMP phosphodiesterase (PDE4) reverses memory deficits associated with NMDA receptor antagonism. Neuropsychopharmacology 23: 198-204.

Zhang, H.T., Zhao, Y., Huang, Y., Dorairaj, N.R., Chandler, L.J., and O'Donnell, J.M. 2004. Inhibition of the phosphodiesterase 4 (PDE4) enzyme reverses memory deficits produced by infusion of the MEK inhibitor U0126 into the CA1 subregion of the rat hippocampus. Neuropsychopharmacology 29: 1432-1439.

Received August 1, 2007; accepted in revised form November 25, 2007. 


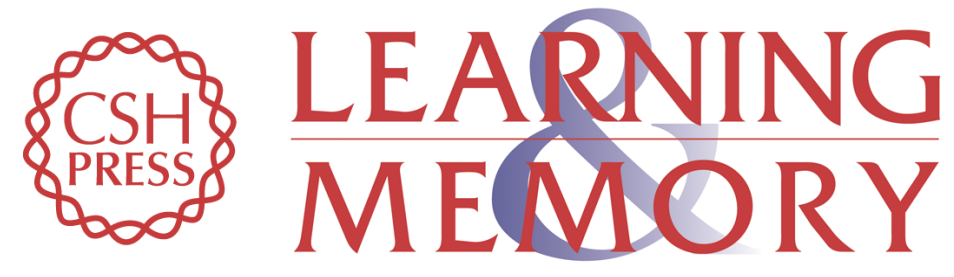

\section{Constitutive activation of the G-protein subunit Gas within forebrain neurons causes PKA-dependent alterations in fear conditioning and cortical Arc mRNA expression}

Michele P. Kelly, York-Fong Cheung, Christopher Favilla, et al.

Learn. Mem. 2008, 15:

Access the most recent version at doi:10.1101//m.723708

References This article cites 67 articles, 26 of which can be accessed free at:

http://learnmem.cshlp.org/content/15/2/75.full.html\#ref-list-1

License

Email Alerting Receive free email alerts when new articles cite this article - sign up in the box at the Service top right corner of the article or click here. 